\title{
Forecasting Black Tea Auction Prices by Capturing Common Seasonal Patterns
}

\author{
D. Induruwage*, C. D. Tilakaratne and S.R.M.S.P. Rajapaksha \\ Department of Statistics, University of Colombo, Colombo 03, Sri Lanka. \\ *Corresponding Author: dilshaniind89@gmail.com
}

Received: 26, August 2015 / Revised: 19, October 2015 / Accepted: 06, January 2016

CIAppStat-SL2015

\begin{abstract}
Tea industry plays a major role in economies of tea producing countries and therefore, it is important to study the behavior of tea auction prices and forecasting tea auction prices for several months. This study investigates whether the use of common seasonal patterns improve the forecasting accuracy of black tea auction prices with a special emphasis on forecasting prices of the Colombo tea auction. Monthly black tea auction prices of eight auction centers were used for the analysis. Seasonally unadjusted series were tested for seasonal unit roots using the procedure proposed by Beaulieu and Miron in 1992. Seasonal unit root tests provided evidence of presence of common seasonal cycles in monthly black tea auction prices of Colombo, Kolkata and Guwahati centers at six cycles per year. A seasonal cointegration relationship was identified in aforesaid three tea auction prices which made it possible to fit a Seasonal Error Correction Model (SECM). Similar analysis was carried out for seasonally adjusted data. It was found that all three seasonally adjusted series were I(1) and therefore, series were tested for cointegration relationships. A cointegration relationship among these series was evident and hence Vector Error Correction (VEC) model was fitted. Adequacy of the fitted SECM and VEC models were tested, and unit root tests and correlograms suggested that the error series were stationary. Using the fitted SECM and VEC models, prices for several months were forecasted. The accuracy of the forecasts was tested using Mean Square Error (MSE) and Mean Absolute Percentage Error (MAPE). Both measures confirmed that seasonally unadjusted model produces more accurate forecasts than those obtained from the other model, during the study period.

Keywords: Seasonal Unit Roots, Seasonal Cointegration, Seasonal Error Correction Models, Vector Error Correction Model, Forecasting, Tea auction prices
\end{abstract}




\section{Introduction}

Tea industry plays a major role in economies of tea producing countries like Sri Lanka. Therefore, researchers are interested in studying the tea industry and behavior of tea auction prices. Tea auction prices are naturally noisy and nonstationary in nature (Hettiarachchi \& Banneheka, 2013) and the conventional statistical methods usually do not work. Like most other agricultural time series, tea auction prices too exhibit seasonal behavior. Although tea auction prices have been modeled using different approaches, no research that attempts to capture the seasonality is found in literature. For example, Dharmasena (2003) studied international black tea markets and tested the ability of forecasting tea auction prices using Vector Auto-regression (VAR) models. Hewapathirana and Tilakaratne (2012) explored the temporal behavior of the prices of black tea at the Colombo auction center and assessed the cointegration among the monthly black tea prices at eight international tea auction centers. They used seasonally adjusted data to capture cointegration among the series and forecasted the series using the Vector Error Correction (VEC) models. Hettiarachchi and Banneheka (2012) forecasted the seasonally adjusted prices of the Colombo Tea Auction Center (CTAC) using Time series regression with Generalized Least Squares (GLS) and ANN. Gijo (2011) forecasted the monthly demand for tea in India using Box-Jenkins seasonal autoregressive integrated moving average (SARIMA) model, but did not model the tea auction prices. Nyaga and Doppler (2009) used dynamic models to assess impact of changing tea prices on family income of smallholders in Kenya. They used dynamic models for a period of ten years assuming only the current trend for the entire period.

All these studies used seasonally adjusted data instead of original data since the techniques for directly analyzing seasonal data are still in the developing stage. However, filtering out the seasonal component from data may lead to loss of important information and therefore the true nature of the relationships between these series may not be revealed. Due to William and Hillmer (1984) seasonal adjustment has been used by many as a tool in the absence of proper models for seasonal data and it has brought about simplicity and convenience at the expense of possible loss of information. Seasonally adjusted data are useful to the statistically unsophisticated user only if information loss is small and the disadvantage over unadjusted data comes from the difficulty in estimation of forecast error variances and production of forecast intervals (William and Hillmer, 1984). 
This study uses data without seasonal adjustment to identify the common seasonal patterns of tea auction prices and to detect the true relationships between series. However, none of the previous studies reviewed, included the seasonal component and have only used the trend component of the series. Therefore, this research considerably deviates from past work in this direction and possibly the first attempt on tea auction prices capturing the common seasonality patterns in data.

Thus, the aim of this paper is to forecast tea auction prices by capturing the seasonality rather than adjusting for it, with the special emphasis on forecasting at Colombo center. Furthermore, the study compares the accuracy of the seasonal model with the model fitted for seasonally adjusted data in forecasting the same series.

\section{Methodology}

Monthly tea auction prices (US\$ $/ \mathrm{kg}$ ) at eight auction centers, Colombo (Sri Lanka), Kolkata, Guwahati, Cochin (India), Chittagong (Bangladesh), Jakarta (Indonesia), Mombasa (Kenya) and Limbe (Malawi) were used for this study. Data period considered was from January 2001 to July 2012.

\subsection{Seasonal Unit Roots}

Time series with seasonality may contain unit roots at other frequencies rather than at zero frequency. Several researchers addressed this situation by their empirical studies and testing procedures have been introduced.

Hylleberg, Engle, Granger and Yoo, (1990) proposed a test to detect seasonal unit roots at different seasonal frequencies, as well as at zero frequency. They focused on studying seasonal unit roots for quarterly data. The testing procedure was developed as a representation of rational polynomials and an auto-regression was reformulated by isolating the key unit-root parameters. Beaulieu and Miron (1992) also provided evidence on the presence of seasonal unit roots. They conducted the analysis using the approach developed by Hylleberg et al. (1990) in the case of monthly rather than quarterly data. Beaulieu and Miron (1992) claimed that monthly data consist of zero frequency unit root and eleven seasonal unit roots. They computed the finite sample critical values of the associated test statistics using the Monte Carlo methods. The theory proposed by Beaulieu and Miron (1992) is used for the analysis of seasonal unit roots.

Let $\mathrm{X}_{t}$ be the series of interest, generated by a general autoregression of the form

$$
\varphi(B) X_{t}=\epsilon_{t}
$$


where $\varphi(B)$ is a polynomial in the backshift operator and $\epsilon_{t}$ is a white noise process. Let $\theta_{s}$ be the roots of the characteristic polynomial associated with $\varphi(B)$.

To test the hypothesis that the roots of $\varphi(B)=0$ are on the unit circle against the alternative hypothesis that they are outside the unit circle, the following procedure can be used.

Consider,

$$
\mathrm{X}_{t}=\rho \mathrm{X}_{t-s}+\epsilon_{t}
$$

This is stationary if $\rho<1$, but has unit roots at all frequencies if $\rho=1$. Therefore when $\rho=1$, equation becomes

$$
\begin{aligned}
& \mathrm{X}_{t}=\mathrm{X}_{t-s}+\epsilon_{t} \\
& \left(1-B^{s}\right) \mathrm{X}_{t}=\epsilon_{t}
\end{aligned}
$$

For seasonal integration in monthly data, $\left(1-B^{12}\right)$ is the relevant polynomial. It can be factored as,

$$
\left(1-B^{12}\right)=(1-\mathrm{B})(1+\mathrm{B})\left(1+B^{2}\right)\left(1+\mathrm{B}+B^{2}\right)\left(1-\mathrm{B}+B^{2}\right)\left(1+\sqrt{3} B+B^{2}\right)\left(1-\sqrt{ } 3 B+B^{2}\right)
$$

with corresponding roots, $\theta_{1}=1$ plus the eleven seasonal roots.

For monthly data, seasonal unit roots of the polynomial are (Beaulieu \& Miron, 1992):

$$
\begin{array}{lll}
\theta_{2}=-1 & \theta_{3}=+\mathrm{i} & \theta_{4}=-\mathrm{i} \\
\theta_{5}=-1 / 2(1+\sqrt{ } 3 \mathrm{i}) & \theta_{6}=-1 / 2(1-\sqrt{ } 3 \mathrm{i}) & \\
\theta_{7}=1 / 2(1+\sqrt{ } 3 \mathrm{i}) & \theta_{8}=1 / 2(1-\sqrt{3} \mathrm{i}) & \\
\theta_{9}=-1 / 2(\sqrt{ } 3+\mathrm{i}) & \theta_{10}=-1 / 2(\sqrt{ } 3-\mathrm{i}) & \\
\theta_{11}=1 / 2(\sqrt{ } 3+\mathrm{i}) & \theta_{12}=1 / 2(\sqrt{ } 3-\mathrm{i}), &
\end{array}
$$

with these roots corresponding to $6,3,9,8,4,2,10,7,5,1$, and 11 cycles per year, respectively. The frequencies of these roots are $\pi, \pm \pi / 2, \pm 2 \pi / 3, \pm \pi / 3, \pm 5 \pi / 6$ and $\pm \pi / 6$, respectively.

To know if the polynomial in the backshift operator, $\varphi(B)$ has roots at the zero or at seasonal frequencies, the hypothesis about a particular unit root should be tested, removing the other unit roots for the moment.

The testing procedure developed by Hylleberg et al. (1990), consists basically of linearizing the polynomial $\varphi(B)$ around the zero frequency unit roots and the (s 1) seasonal unit roots. 
Accordingly, $\varphi(B)$ can be written as:

$$
\varphi(B)=\sum_{k=1}^{S} \lambda_{k} \Delta(B) \frac{1-\delta_{k}(B)}{\delta_{k}(B)}+\Delta(B) \varphi^{*}(\mathrm{~B})
$$

where,

$\delta_{k}(B)=1-\frac{1}{\theta_{k}} B, \quad \quad \lambda_{k}=\frac{\varphi\left(\theta_{k}\right)}{\prod_{j \neq k} \delta_{j}\left(\theta_{k}\right)}, \quad \Delta(B)=\prod_{k=1}^{S} \delta_{k}(B)$.

$\varphi^{*}(\mathrm{~B})$ is a remainder with roots outside the unit circle, and $\theta_{k}$ are the zero frequency unit root plus the $(s-1)$ seasonal unit roots. In the case of monthly data, substitution of Equation (4) in to Equation (1) gives,

$\sum_{k=1}^{S} \lambda_{k} \Delta(B) \frac{1-\delta_{k}(B)}{\delta_{k}(B)} \mathrm{X}_{t}+\Delta(B) \varphi^{*}(\mathrm{~B}) \mathrm{X}_{t}=\epsilon_{t}$

$\varphi^{*}(\mathrm{~B})\left[\Delta(B) \mathrm{X}_{t}\right]=\sum_{k=1}^{S}\left[-\lambda_{k}\right]\left[\Delta(B) \frac{1-\delta_{k}(B)}{\delta_{k}(B)} \mathrm{X}_{t}\right]+\epsilon_{t}$

$\varphi^{*}(\mathrm{~B})\left[\left(1-B^{12}\right) \mathrm{X}_{t}\right]=-\lambda_{1}\left(1-B^{12}\right) \frac{B}{(1-B)} \mathrm{X}_{t^{-}} \ldots-\lambda_{12}\left(1-B^{12}\right) \frac{2 B}{(\sqrt{3-i}-2 B)} \mathrm{X}_{t}+\epsilon_{t}$

$$
\varphi^{*}(\mathrm{~B}) Y_{13 t}=\sum_{k=1}^{12} \pi_{k} Y_{k, t-1}+\epsilon_{t}
$$

where, $\pi_{k}$ is the coefficients associated with each unit root by converting complex value $\lambda_{k}$ and $Y_{k, t-1}$ is the series generated by applying backshift operators to $X_{t}$.

In order to test hypotheses of various unit roots, Equation (5) can be estimated using Ordinary Least Squares (OLS) method.

\subsection{Testing for Seasonal Unit Roots}

The null and the alternative hypotheses for testing seasonal unit roots are:

$H_{0}$ : There is a unit root at frequency $\theta_{s}$

$H_{1}$ : There is no unit root at frequency $\theta_{s}$

where $\theta_{s}=0, \pi, \pm \pi / 2, \pm 2 \pi / 3, \pm \pi / 3, \pm 5 \pi / 6, \pm \pi / 6$.

Testing the hypothesis of a unit root at zero frequency is equivalent to testing the significance of the coefficient $\pi_{1}\left(\pi_{1}\right.$ is the coefficient associated with zero frequency unit root), and this can be done using a $t$ test. Since the test simply examines the $\pi_{1}=0$ against the alternative $\pi_{1} \neq 0$, a t statistics can be used.

If $\pi_{1}=0$ then $\varphi^{*}(\mathrm{~B})$ (remainder with roots outside the unit circle) does not contain any zero frequency unit root which means series contains a zero frequency unit root. 


\section{Root $\theta_{1}$}

$H_{0}: \pi_{1}=0$ vs. $H_{1}: \pi_{1} \neq 0$

T-test can be used to test the significance of the coefficient $\pi_{2}$, to test the existence of a unit root at the $\pi$ frequency.

\section{Root $\boldsymbol{\theta}_{2}$}

$H_{0}: \pi_{2}=0$ vs. $H_{1}: \pi_{2} \neq 0$

The presence of unit roots at frequencies $\pm \pi / 2, \pm 2 \pi / 3, \pm \pi / 3, \pm 5 \pi / 6$ and $\pm \pi / 6$, can be tested using F-test for the joint hypothesis. F test is used, since the null hypothesis examines the $\pi_{\mathrm{i}}=0$ and $\pi_{\mathrm{j}}=0$ against the alternative $\pi_{\mathrm{i}} \neq 0$ and $\pi_{\mathrm{j}} \neq 0$ where $i$ and $j$ are pairs $(3,4),(5,6),(7,8) .(9,10)$ and $(11,12)$ (Beaulieu and Miron, 1992).

\subsection{Seasonal Cointegration}

If two or more time series share a common seasonal unit root at a certain frequency and the linear combination of this series may not present any of the seasonal unit roots, then series are said to be seasonally cointegrated. The presence of seasonal unit roots suggests the need to test for seasonal cointegration. The concept of cointegration has been extended for modelling seasonality in Hylleberg et al. (1990) and also the test for seasonal cointegration has been mainly revealed by Engle, Granger, Hylleberg, and Lee, (EGHL; 1993).

Engle et al. (1993) proposed a two-step method for testing for the presence of seasonal and non-seasonal cointegration relationships. The test proposed by Engle et al. (1993) was based on a residual test. Tests for cointegration at the zero and seasonal frequencies were conducted by testing the residuals from the cointegrating regressions. The test was meant to detect any remaining unit roots at the zero and seasonal frequencies.

Let $\mathrm{Z}_{j t}$ and $\mathrm{P}_{j t}$ be the series of interest, both the series contain common seasonal unit roots at particular frequencies. Following EGHL (1993), the cointegration and seasonal cointegration tests were estimated using the regression equations,

$$
\begin{gathered}
\omega_{1 t}=Z_{1 t}-\alpha_{1} P_{1 t} \\
\omega_{2 t}=Z_{2 t}-\alpha_{2} P_{2 t} \\
\omega_{i t}=Z_{i t}-\alpha_{3} P_{i t}-\alpha_{4} Z_{i t-1}-\alpha_{5} P_{i t-1}
\end{gathered}
$$

where, $\mathrm{Z}_{j t}$ and $\mathrm{P}_{j t}(j=1,2$, and $i$ where $i=3,4,5,6,7)$ represent the transformed series at various frequencies. $Z_{j t}$ and $\mathrm{P}_{j t}$ should be adjusted as only keeping the unit roots at common frequencies and removing all the other unit roots. 
Cointegration of Equation (6) implies long run equilibrium at the zero frequency. To test cointegration at 0 frequency, $Z_{1 t}$ and $P_{1 t}$ variables are adjusted appropriately. Seasonal filters apply to remove all the unit roots except 0 frequency unit root as given below (EGHL; 1993):

$Z_{1 t}=P_{1 t}=\left(1+\mathrm{B}+B^{2}+B^{3}+B^{4}+B^{5}+B^{6}+B^{7}+B^{8}+B^{9}+B^{10}+B^{11}\right) X_{t}$.

Cointegration of Equation (7) implies seasonal cointegration at $\pi$ frequency. To test seasonal cointegration at $\pi$ frequency, $Z_{2 t}$ and $P_{2 t}$ variables need to be adjusted appropriately. Seasonal filters apply to remove all the unit roots except $\pi$ frequency unit root are:

$Z_{2 t}=P_{2 t}=\left(1-\mathrm{B}+B^{2}-B^{3}+B^{4}-B^{5}+B^{6}-B^{7}+B^{8}-B^{9}+B^{10}-B^{11}\right) X_{t}$.

Cointegration of Equation (8) implies seasonal cointegration at $\pm \frac{\pi}{2}, \pm \frac{2 \pi}{3}, \pm \frac{\pi}{3}$, $\pm \frac{5 \pi}{6}, \pm \frac{\pi}{6}$, frequencies. To test seasonal cointegration at these frequencies, $Z_{i t}$ and $P_{i t}$ variables should be adjusted appropriately. Appropriate seasonal filters are applied to remove all the unit roots except the frequency of interest.

For example, to test cointegration at $\pm \frac{\pi}{2}$ frequency unit roots, all the other unit roots are removed except $\pm \frac{\pi}{2}$ unit roots and then using the filter:

$Z_{3 t}=P=\left(1-B^{2}+B^{4}-B^{6}+B^{8}-B^{10}\right) X_{t}$.

The EGHL (1993) test is a residual test and tests for cointegration at the zero and seasonal frequencies were conducted by testing the residuals from the cointegrating regression. The test is meant to detect any remaining unit roots at zero and seasonal frequencies. If the residuals of cointegration regressions do not contain any zero or seasonal frequency then the series are seasonally cointegrated.

\subsection{Seasonal Error Correction Model}

When the seasonal cointegration relationships are established, the SECM can be estimated. The SECM is the second stage of the Engle et al. (1993) cointegration procedure. The Error Correction (EC) terms from the seasonal cointegrating equations are used in the SECM.

SECM to be estimated is of the form,

$$
\begin{array}{r}
\Delta_{12} X_{1 t}=\lambda_{1} \omega_{1, t-1}+ \\
\lambda_{2} \omega_{2, t-1}+\sum_{i=3}^{7} \delta_{i} \omega_{i, t-1}+\sum_{i=3}^{7} \lambda_{i} \omega_{i, t-2}+ \\
\sum_{i=1}^{q} \alpha_{i} \Delta_{12} X_{1, t-i}+\sum_{i=1}^{q} \beta_{i} \Delta_{12} X_{2, t-i}+\epsilon_{t}^{*}
\end{array}
$$


where, $X_{1, t}$ and $X_{2, t}$ are the original series which contained common seasonal unit roots

$\omega_{i}$ is the error correction term

$\mathrm{q}$ is the maximum lag length for each series.

$\epsilon_{t}^{*}$ is a stationary disturbance

$\lambda_{i}$ 's, $\delta_{i}$ 's, $\alpha_{i}$ 's and $\beta_{i}$ 's are to be estimated.

Equation (9) can be estimated using OLS method. Using the estimated model for each series, future values (based on previously observed values) of tea auction prices up to several time periods can be forecasted.

\subsection{Seasonal Adjustment}

The estimation of seasonal variation and the elimination of its impact from a time series is seasonal adjustment. There are several methods to perform seasonal adjustment. One method is TRAMO/SEATS method (Hood, Ashley and Findley, 2000). TRAMO/SEATS method is a parametric method to seasonally adjust the data. The adjustment filter is determined by a model, not a finite set of moving average filters. In practice, SEATS sometimes gives smoother adjustments with smaller revisions for some irregular series.

\subsection{Vector Error Correction Model}

VEC model automatically corrects the deviations from the long run equilibrium. VEC model is given as,

$$
\begin{gathered}
\Delta Y_{n t}=c_{n}+\sum_{i=1}^{q} \beta_{1 t} \Delta Y_{1, t-i}+\sum_{i=1}^{q} \beta_{2 t} \Delta Y_{2, t-i}+\ldots . .+\sum_{i=1}^{q} \beta_{n t} \Delta Y_{n, t-i}+ \\
\gamma_{1} Z_{t-1}+\varepsilon_{n t}
\end{gathered}
$$

where, $Y_{n, t}$ is the original series ( $\mathrm{n}-$ number of series)

$q$ is the maximum lag length for each series.

$\epsilon_{n, t}$ is a stationary disturbance.

$\Delta$ is the first difference operator

$\mathrm{Z}_{t-1}$ is the lagged residual (error correction) term

$\beta_{n t}$ and $\gamma_{1}$ are the coefficients

\subsection{Lag Selection Criteria}

When fitting the SECM or VECM, it is needed to include lagged values of the time series as independent variables. To select how many lags are to be included, several lag selection criteria can be used. The most common and most powerful lag selection criteria is Schwarz Criteria (SC). 
Lag length is identified by using the model which gives minimum SC value. The $\mathrm{SC}$ value is calculated by the formula:

$\mathrm{SC}=-2(\log$ Likelihood $)+$ number of parameters* $\log$ (number of observations)

\subsection{Adequacy of the Models}

Adequacy tests for the SECM models are still in the developing stage. Test for the stationarity of the error term is the only model adequacy test available at present. Therefore, to test the adequacy of the fitted SECM and VEC models, error terms of the models can be examined. Additionally, Portmanteau Autocorrelation Test and Autocorrelation LM Test can be used to test the adequacy of the VEC model. If a model is adequate, then error terms should be stationary. Stationarity of the error terms are tested using the seasonal unit root test and using the correlograms. Mean Square Error (MSE) and Mean Absolute Percentage Error (MAPE) of the forecasted values can be used to test the forecasting accuracy of the fitted models.

\section{Results and Discussion}

\subsection{Modelling Seasonally unadjusted Data}

Time series plots of the considered series exhibit seasonal behavior, indicating the possibility to existence of unit roots at other frequencies rather than at zero frequency.

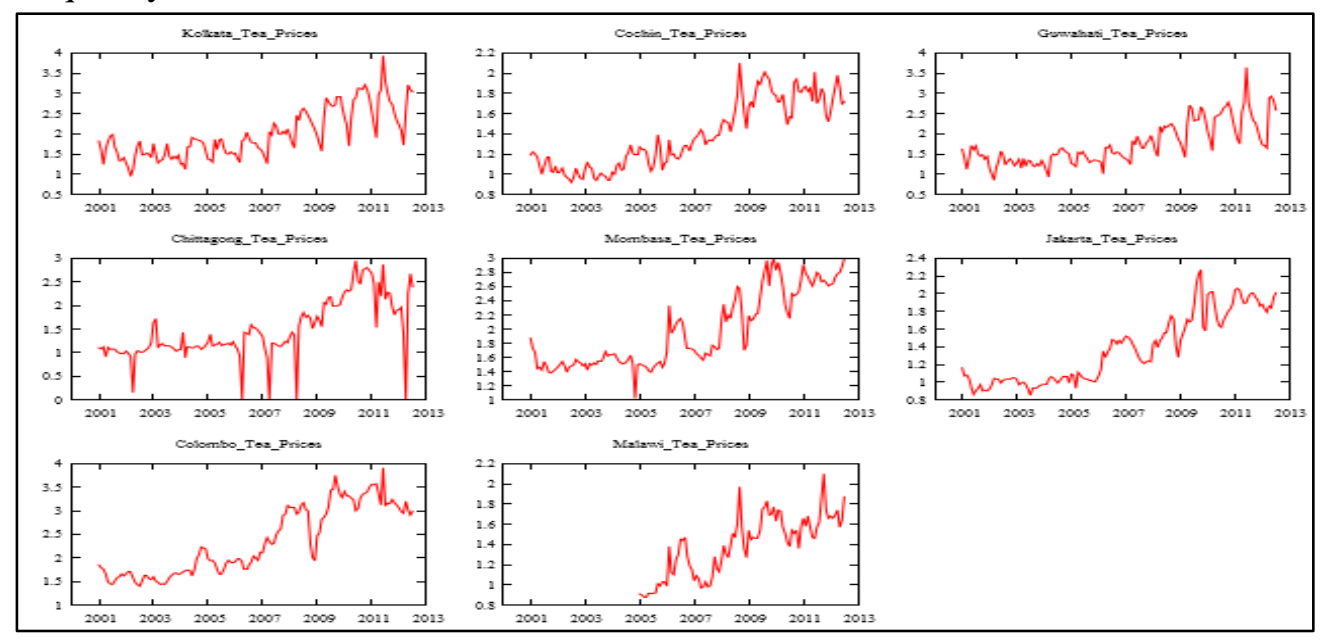

Figure 1: Time series plots of tea auction prices

To address the seasonality in the data, seasonal unit root tests were performed instead of zero frequency unit root tests. Tea auction prices of eight auction centers from January 2001 to July 2012, were tested for the presence of unit roots at zero and eleven seasonal frequencies.

Hypothesis for testing Seasonal Unit Roots, 
$H_{0}$ : There is a unit root at frequency $\theta_{k}$

$H_{1}$ : There is no unit root at frequency $\theta_{k}$

where $\theta_{k}=0, \pi, \pm \pi / 2, \pm 2 \pi / 3, \pm \pi / 3, \pm 5 \pi / 6, \pm \pi / 6$

Table 1 summarizes the results of testing the above hypothesis for tea auction prices at Colombo center.

Table 1: Seasonal unit root test statistics for tea prices at Colombo center

\begin{tabular}{|l|l|l|l|}
\hline Angular Frequency & Statistic & Critical values (145, 1\%) & p-value \\
\hline 0 & $\mathrm{t} 1=-0.57$ & 3.35 & 0.8547 \\
\hline$\pi$ & $\mathrm{t} 2=-2.42$ & 2.48 & 0.0520 \\
\hline$\pm \pi / 6$ & $\mathrm{~F} 1=12.31$ & 4.60 & $0.0000^{*}$ \\
\hline$\pm \pi 3$ & $\mathrm{~F} 2=7.26$ & 4.60 & $0.0009^{*}$ \\
\hline$\pm \pi / 2$ & $\mathrm{~F} 3=16.22$ & 4.60 & $0.0000^{*}$ \\
\hline $\pm 2 \pi 3$ & $\mathrm{~F} 4=14.68$ & 4.60 & $0.0000^{*}$ \\
\hline $\pm 5 \pi / 6$ & $\mathrm{~F} 5=11.05$ & 4.60 & $0.0000^{*}$ \\
\hline
\end{tabular}

Colombo series failed to reject $H_{0}$ at frequencies 0 and $\pi$ at $5 \%$ significant level. It showed evidence of having zero frequency unit root and $\pi$ frequency seasonal unit root.

Table 2 presents the summary of seasonal unit root tests applied to eight series.

Table 2: Summary of the Seasonal unit root tests of eight series

\begin{tabular}{|l|l|l|l|l|l|l|l|}
\hline Series & $\mathbf{0}$ & $\boldsymbol{\pi}$ & $\mathbf{\pi} \mathbf{6}$ & $\mathbf{\pm} \boldsymbol{\pi} \mathbf{3}$ & $\mathbf{\pm} \boldsymbol{\pi} \mathbf{2}$ & $\mathbf{\pm 2 \pi \boldsymbol { 3 }}$ & $\mathbf{\pm 5 \pi} \mathbf{6}$ \\
\hline Kolkata & $\sqrt{ }$ & $\sqrt{ }$ & $\sqrt{ }$ & $\sqrt{ }$ & $\sqrt{ }$ & $\sqrt{ }$ & $\sqrt{ }$ \\
\hline Cochin & $\sqrt{ }$ & & & & & & \\
\hline Guwahati & $\sqrt{ }$ & $\sqrt{ }$ & $\sqrt{ }$ & $\sqrt{ }$ & $\sqrt{ }$ & $\sqrt{ }$ & $\sqrt{ }$ \\
\hline Chittagong & $\sqrt{ }$ & & $\sqrt{ }$ & $\sqrt{ }$ & $\sqrt{ }$ & $\sqrt{ }$ & \\
\hline Mombasa & $\sqrt{ }$ & & & $\sqrt{ }$ & & & \\
\hline Jakarta & $\sqrt{ }$ & & & $\sqrt{ }$ & $\sqrt{ }$ & $\sqrt{ }$ & $\sqrt{ }$ \\
\hline Colombo & $\sqrt{ }$ & $\sqrt{ }$ & & & & & \\
\hline Malawi & $\sqrt{ }$ & & $\sqrt{ }$ & $\sqrt{ }$ & & & \\
\hline
\end{tabular}

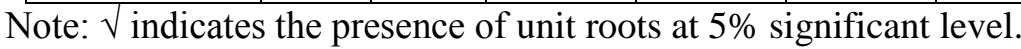

According to Table 2, all the time series contains zero frequency unit root. Cochin series contains only the unit root at zero frequency, which suggested the absence of seasonal component. Kolkata and Guwahati series contains all twelve unit roots. Colombo series shows evidence for the presence of unit roots at the zero and $\pi$ frequencies. In this study a special attention was given to forecast Colombo tea auction prices capturing common seasonal patterns. The only seasonal unit root present in the Colombo series is at the $\pi$ frequency. Therefore, series which share $\pi$ frequency unit root selected for the further analysis. 
Colombo, Kolkata and Guwahati series contained common seasonal unit roots at $\pi$ frequency, and therefore, these three series were used for the further analysis.

Seasonal cointegration relationships were tested for these three series with common seasonal unit roots at $\pi$ frequency. These series also share common unit root at zero frequency. Therefore, cointegration at zero frequency unit root was tested before testing for seasonal cointegration at $\pi$ frequency unit root. To test the cointegration at zero frequency unit root, three series were adjusted keeping only the zero unit root by removing all the seasonal unit roots present in the series. Colombo series have unit roots at zero frequency and $\pi$ frequency. To keep only the zero frequency unit root, $\pi$ frequency unit root had to be removed from this series. In order to remove it $(1+\mathrm{B})$ filter was used. Kolkata and Guwahati series consist of zero frequency unit root and eleven seasonal unit roots. To keep only the zero frequency unit root, eleven seasonal unit roots were filtered. Hence, the filter, $\left(1+\mathrm{B}+B^{2}+B^{3}+B^{4}+B^{5}+B^{6}+B^{7}+B^{8}+B^{9}+B^{10}+B^{11}\right)$ was applied.

To test seasonal cointegration at $\pi$ frequency unit root, three series were adjusted keeping only the $\pi$ frequency unit root and removing all the roots present in the series. To keep only the $\pi$ frequency unit root, zero frequency unit root has to be removed from the Colombo series. In order to remove it (1-B) filter was used. Kolkata and Guwahati series contained zero frequency unit root and eleven seasonal unit roots. To keep only the $\pi$ frequency unit root, filter the eleven seasonal unit roots. Therefore, $\left(1-\mathrm{B}+B^{2}-B^{3}+B^{4}-B^{5}+B^{6}-B^{7}+B^{8}-B^{9}+B^{10}-\right.$ $B^{11}$ ) filter was used.

After adjusting the series for each unit root, seasonal cointegration procedure was carried out. Using the procedure suggested by Engle et al. (1993), the cointegration and seasonal cointegration tests were estimated using the regression equations

$$
\begin{aligned}
& \omega_{1 t}=\text { Colombo_zero }_{t}-\alpha_{1} \text { Kolkata_zero }_{t}-\alpha_{2} \text { Guwahati_zero } t \\
& \omega_{2 t}=\text { Colombo_pi } i_{t}-\alpha_{3} K_{\text {Kolkata_pi }}-\alpha_{4} G u w a h a t i \_p i_{t}
\end{aligned}
$$

where, $\omega_{1 t}$ and $\omega_{2 t}$ are the residual terms of the models.

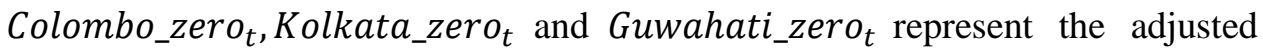
series at zero frequency

Colombo_pi $i_{t}, K o l k a t a \_p i_{t}$ and Guwahati_pi $i_{t}$ represent the adjusted series at $\pi$ frequency. 
$\omega_{1 t}$ and $\omega_{2 t}$ are expected to be stationary, at all frequencies. They were found to be stationary as expected. Therefore, a linear combination of above adjusted series were found to be stationary indicating the presence of a seasonal cointegration relationship among them.

Table 3 shows the seasonal unit roots of the error term of the cointegration relationship between Colombo, Kolkata and Guwahati series.

According to Table 3, residual term $\omega_{2 t}$ does not contain any unit roots at $5 \%$ significance level, indicating that the linear combination is stationary. Therefore, seasonal cointegration is found to be present for this linear relationship.

Table 3: Seasonal unit root test for residuals of $\pi$ frequency unit root.

\begin{tabular}{|c|c|c|c|c|c|c|c|}
\hline \multicolumn{8}{|c|}{ Angular Frequency } \\
\hline & 0 & $\Pi$ & $\pm \pi / 6$ & $\pm \pi 3$ & $\pm \pi / 2$ & $\pm 2 \pi 3$ & $\pm 5 \pi / 6$ \\
\hline 茪 & $\begin{array}{l}\mathrm{t} 1 \\
\mathrm{p} \text {-value }\end{array}$ & $\begin{array}{l}\mathrm{t} 2 \\
\mathrm{p} \text {-value }\end{array}$ & $\begin{array}{l}\text { F1 } \\
\text { p-value }\end{array}$ & $\begin{array}{l}\mathrm{F} 2 \\
\mathrm{p} \text {-value }\end{array}$ & $\begin{array}{l}\text { F3 } \\
\text { p-value }\end{array}$ & $\begin{array}{l}\text { F4 } \\
\text { p-value }\end{array}$ & $\begin{array}{l}\text { F5 } \\
\text { p-value }\end{array}$ \\
\hline$\omega_{2 t}$ & $\begin{array}{l}-4.29 \\
0.0004 *\end{array}$ & $\begin{array}{l}-2.24 \\
0.0087 *\end{array}$ & $\begin{array}{l}10.84 \\
0.0000 *\end{array}$ & $\begin{array}{l}6.97 \\
0.0012 *\end{array}$ & $\begin{array}{l}13.79 \\
0.0000 *\end{array}$ & $\begin{array}{l}12.34 \\
0.0000 *\end{array}$ & $\begin{array}{l}8.70 \\
0.0003 *\end{array}$ \\
\hline
\end{tabular}

Note: $*$ indicates the rejection of the null hypothesis at $5 \%$ significant level.

The seasonal cointegration relationship is given by:

$\widehat{\omega_{2 t}}=$ Colombo_pi ${ }_{t}-0.0501 * K_{\text {Kolkata_pi }}-0.0005 *$ Guwahati_pi $t-0.0099$

Three series Colombo, Kolkata and Guwahati were individually non-stationary with $\pi$ frequency unit root. However, linear combination of these three series became stationary. So, for this linear combination seasonal cointegration is present. Therefore a Seasonal Error Correction Model (SECM) was fitted with the Error Correction (EC) term, $\omega_{2 \text { t. }}$ SECM models were fitted for these three series using the error correction term found in seasonal cointegration relationship.

SECM to be estimated is of the form:

$$
\begin{array}{r}
\Delta_{12} X_{n t}=\lambda_{n} \omega_{2, t-1}+\sum_{i=1}^{q} \beta_{1 i} \Delta_{12} X_{1, t-i}+\sum_{i=1}^{q} \beta_{2 i} \Delta_{12} X_{2, t-i}+ \\
\sum_{i=1}^{q} \beta_{3 i} \Delta_{12} X_{3, t-i}+\epsilon_{n t}^{*}
\end{array}
$$

where, $\mathrm{n}=1,2,3$ (series no.)

$q$ is the maximum lag length 
$\epsilon_{n t}^{*}$ is a stationary disturbance

$X_{n t}$ is the original series of Colombo, Kolkata and Guwahati.

Considering each series as the dependent variable, three equations were estimated using OLS method. Three models were fitted namely Colombo model, Kolkata model and Guwahati model. For each series the suitable lag length was assigned based on SC criteria.

$\Delta_{12}$ Colombo $_{t}=\lambda_{n} \omega_{2, t-1}+\sum_{i=1}^{q} \beta_{1 i} \Delta_{12}$ Colombo $_{t-i}+\sum_{i=1}^{q} \beta_{2 i} \Delta_{12}$ Kolkata $_{t-i}+$ $\sum_{i=1}^{q} \beta_{3 i} \Delta_{12}$ Guwahati $_{t-i}+\epsilon_{n t}^{*}$

$\Delta_{12}$ Kolkata $_{t}=\lambda_{n} \omega_{2, t-1}+\sum_{i=1}^{q} \beta_{1 i} \Delta_{12}$ Colombo $_{t-i}+\sum_{i=1}^{q} \beta_{2 i} \Delta_{12}$ Kolkata $_{t-i}+$ $\sum_{i=1}^{q} \beta_{3 i} \Delta_{12}$ Guwahati $_{t-i}+\epsilon_{n t}^{*}$

$\Delta_{12}$ Guwahati $_{t}=\lambda_{n} \omega_{2, t-1}+\sum_{i=1}^{q} \beta_{1 i} \Delta_{12}$ Colombo $_{t-i}+\sum_{i=1}^{q} \beta_{2 i} \Delta_{12}$ Kolkata $_{t-i}+$ $\sum_{i=1}^{q} \beta_{3 i} \Delta_{12}$ Guwahati $_{t-i}+\epsilon_{n t}^{*}$

Corresponding coefficients of the fitted SECM models are shown in Table 4.

Table 4: Coefficients of the fitted SECM Models

\begin{tabular}{|l|l|l|l|}
\hline \multirow{2}{*}{$\begin{array}{l}\text { Independent } \\
\text { Variables }\end{array}$} & \multicolumn{3}{|c|}{ Dependent Variable } \\
\cline { 2 - 4 } & $\left(1-\mathrm{B}^{2}\right)$ Colombo & $\left(1-\mathrm{B}^{12}\right)$ Kolkata & $\left(1-\mathrm{B}^{12}\right)$ Guwahati \\
\hline $\boldsymbol{\omega}_{2, \boldsymbol{t}-\mathbf{1}}$ & 0.823034 & 0.00909 & 0.092972 \\
\hline$\left(1-\mathrm{B}^{12}\right)$ Guwahati $_{\mathrm{t}-1}$ & -0.167529 & 0.149709 & 0.394906 \\
\hline$\left(1-\mathrm{B}^{12}\right)$ Guwahati $_{\mathrm{t}-2}$ & -0.212725 & -0.717387 & -0.662762 \\
\hline$\left(1-\mathrm{B}^{12}\right)$ Colombo $_{\mathrm{t}-1}$ & 0.184254 & -0.034221 & -0.128137 \\
\hline$\left(1-\mathrm{B}^{12}\right)$ Colombo $_{\mathrm{t}-2}$ & -0.071081 & 0.178708 & 0.221205 \\
\hline$\left(1-\mathrm{B}^{12}\right)$ Kolkata $_{\mathrm{t}-1}$ & -0.051728 & 0.462175 & 0.258241 \\
\hline$\left(1-\mathrm{B}^{12}\right)$ Kolkata $_{\mathrm{t}-2}$ & 0.380610 & 0.760869 & 0.621245 \\
\hline
\end{tabular}

The SECM can be used to determine the speed of adjustment. The speed of adjustment determines the rate at which the dependent variable corrects the short run deviations. The magnitude and the sign of the coefficients of the seasonal error correction terms suggests the speed of adjustment as they co-move towards 
each other. Prices of the Colombo center will come to the equilibrium status quicker than prices of other two centers as it has the highest $\lambda_{n}$ value while prices of Kolkata center will take longer time to adjust than those of other two series.

Error terms of the three models were examined to test the adequacy of the fitted three models. Error terms should be stationary disturbances. Stationarity of the error terms were tested using the seasonal unit roots test and correlograms.

Table 5 summarizes the seasonal unit roots test statistics of residual terms.

$H_{0}$ : There is a unit root at frequency $\theta_{k}$

$H_{1}$ : There is no unit root at frequency $\theta_{k}$

Table 5: Seasonal unit root test statistic for error term of Colombo model

\begin{tabular}{|l|l|l|}
\hline $\begin{array}{l}\text { Angular } \\
\text { Frequency }\end{array}$ & Statistic & p-value \\
\hline $\mathbf{0}$ & $\mathrm{t} 1=-3.54$ & $0.0048^{*}$ \\
\hline $\boldsymbol{\pi}$ & $\mathrm{t} 2=-2.00$ & $0.0039^{*}$ \\
\hline$\pm \boldsymbol{\pi} \mathbf{6}$ & $\mathrm{F} 1=11.71$ & $0.0000^{*}$ \\
\hline$\pm \boldsymbol{\pi} \mathbf{3}$ & $\mathrm{F} 2=4.05$ & $0.0088^{*}$ \\
\hline$\pm \boldsymbol{\pi} \mathbf{2}$ & $\mathrm{F} 3=10.20$ & $0.0000^{*}$ \\
\hline$\pm \mathbf{2} \boldsymbol{\pi} \mathbf{3}$ & $\mathrm{F} 4=7.81$ & $0.0006^{*}$ \\
\hline$\pm \mathbf{5} \boldsymbol{\pi} \mathbf{6}$ & F5=6.01 & $0.0030^{*}$ \\
\hline
\end{tabular}

Note: * indicates the rejection of the null hypothesis at 5\% significant level.

According to Table 5, error term of Colombo model does not consist of any seasonal unit roots and zero unit root at 5\% significant level, which suggested that the error term of the Colombo model is stationary and hence the model is adequate. Similarly other two models were found to be adequate. Therefore, fitted models were used to forecast the monthly tea auction prices from August 2012 to January 2013. Out-of-sample forecast was performed on an expanding sample of data.

Table 6 presents MSE, MAPE and MAE of the forecasts obtained by the three fitted models. Among the three models, forecasting accuracy is higher for Colombo model. 
Table 6: MSE, MAPE and MAE values of the fitted models

\begin{tabular}{|l|l|l|l|}
\hline Model & MSE & MAPE & MAE \\
\hline Colombo & 0.0281 & 0.0447 & 0.1439 \\
\hline Kolkata & 0.4476 & 0.2198 & 0.6139 \\
\hline Guwahati & 0.0587 & 0.0875 & 0.2130 \\
\hline
\end{tabular}

\subsection{Modelling Seasonally Adjusted Data}

To analyze seasonally adjusted data, series were seasonally adjusted using TRAMO/SEATS method. After the adjustment, all the eight series were free from seasonality and to investigate the stationarity of the series, Augmented Dickey Fuller (ADF) test was applied to each series.

Table 7 summarizes the Augmented Dickey Fuller (ADF) test results. All the original series are non-stationary whereas the first differenced series are stationary. Therefore, these series are integrated of order one.

Table 7: ADF Test Results

\begin{tabular}{|l|l|l|l|}
\hline Series & ADF (P-value) & $\begin{array}{l}\text { First differenced } \\
\text { series }\end{array}$ & ADF (P-value) \\
\hline Kolkata_SA & 0.8614 & d(Kolkata_SA) & 0.0000 \\
\hline Cochin & 0.8778 & d(Cochin) & 0.0000 \\
\hline Guwahati_SA & 0.7528 & d(GuwahatiSA) & 0.0000 \\
\hline Chittagong_SA & 0.8280 & d(Chittagong_SA) & 0.0000 \\
\hline Mombasa_SA & 0.7972 & d(Mombasa_SA) & 0.0000 \\
\hline Jakarta_SA & 0.9275 & d(Jakarta_SA) & 0.0000 \\
\hline Colombo_SA & 0.7914 & d(Colombo_SA) & 0.0000 \\
\hline Malawi_SA & 0.7896 & d(Malawi_SA) & 0.0000 \\
\hline
\end{tabular}

Although the seven series were individually non-stationary, their linear combination may be stationary and hence checked for the cointegration. When checking for the cointegration relationship only the three series Colombo, Kolkata and Guwahati were used in order to match with analysis done in Section 3.1. Johansen cointegration test was performed to test the cointegration among these series.

Results suggested a cointegration relationship among the selected series. Therefore, a Vector Error Correction (VEC) model was fitted to the three original series. Table 8 gives a summary of the fitted VEC model. 
Table 8: Summary of the Fitted VEC Model

\begin{tabular}{|c|c|c|c|}
\hline \multirow{2}{*}{$\begin{array}{c}\text { Independent } \\
\text { Variables }\end{array}$} & \multicolumn{3}{|c|}{ Dependent Variables } \\
\cline { 2 - 4 } & $\Delta Y_{1 t}$ & $\Delta Y_{2 t}$ & $\Delta Y_{3 t}$ \\
\hline$Z_{t-1}$ & -0.003814 & 0.087122 & 0.018239 \\
\hline$\Delta Y_{1, t-1}$ & 0.042686 & -0.122897 & -0.034477 \\
\hline$\Delta Y_{2, t-1}$ & -0.364322 & -0.115458 & -0.243205 \\
\hline$\Delta Y_{3, t-1}$ & -0.304773 & -0.214978 & -0.470801 \\
\hline $\mathrm{C}_{\mathrm{n}}$ & 0.011097 & 0.007402 & 0.007575 \\
\hline
\end{tabular}

where, $Y_{1 t}-$ Colombo series, $Y_{2 t}-$ Guwahati series, $Y_{3 t}$ - Kolkata series

The residual series of these models were tested for unit roots and found to be stationary. Additionally, Portmanteau Autocorrelation Test and Autocorrelation LM Test suggested that the fitted models are adequate. Therefore, these fitted models were used for forecasting black tea auction prices from August 2012 to January 2013. Out-of-sample forecast was performed on an expanding sample of data.

Forecasting accuracy of the two models fitted using seasonally unadjusted data and seasonally adjusted data were compared. Figure 2 represents the forecasting results from the models fitted to seasonally unadjusted and adjusted Colombo Series.

Figure 2 depicts that in most of the cases forecasted values form the SECM model follow the same pattern as actual series with slight fluctuations. However, predicted values form VEC model along with the added seasonal effect do not follow the pattern of actual series. Forecasted values for seasonal data and last six actual data points represent an increasing trend but predicted values for seasonally adjusted data follows a decreasing trend pattern. 


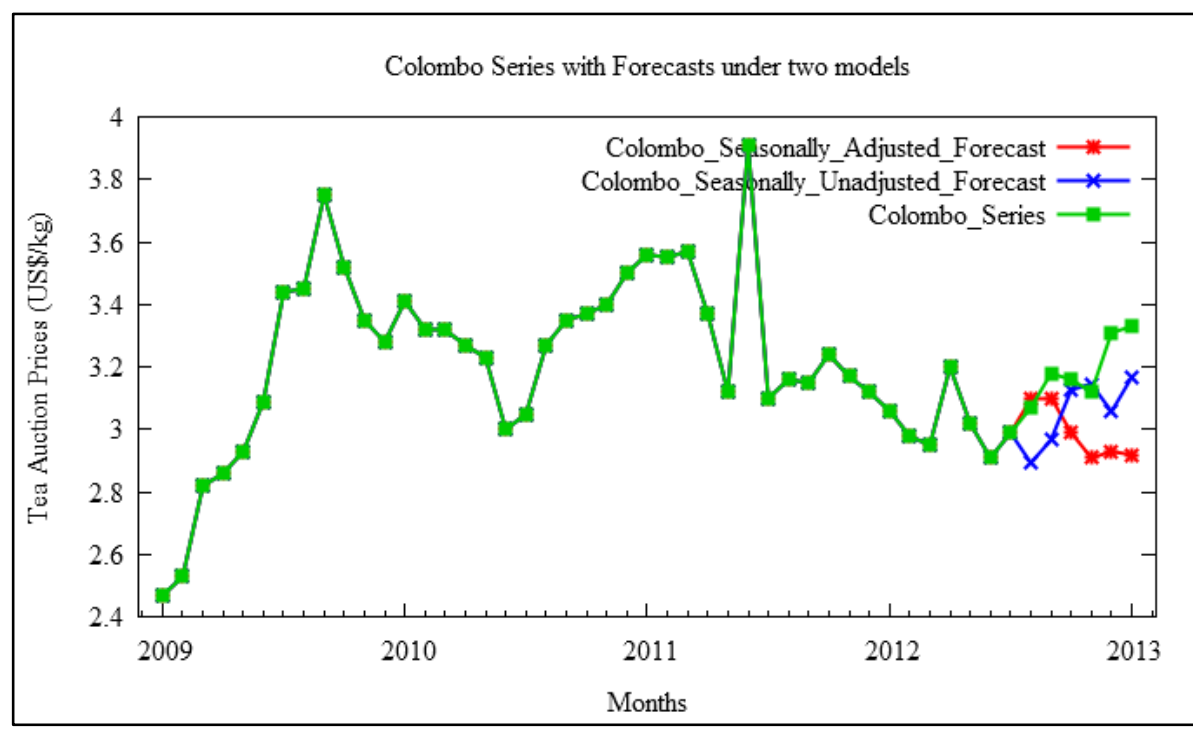

Figure 2: Time series plot of Colombo series with forecasts obtained from the two models

Figure 3 represents the forecasting results obtained from the models fitted to seasonally unadjusted and adjusted Kolkata Series.

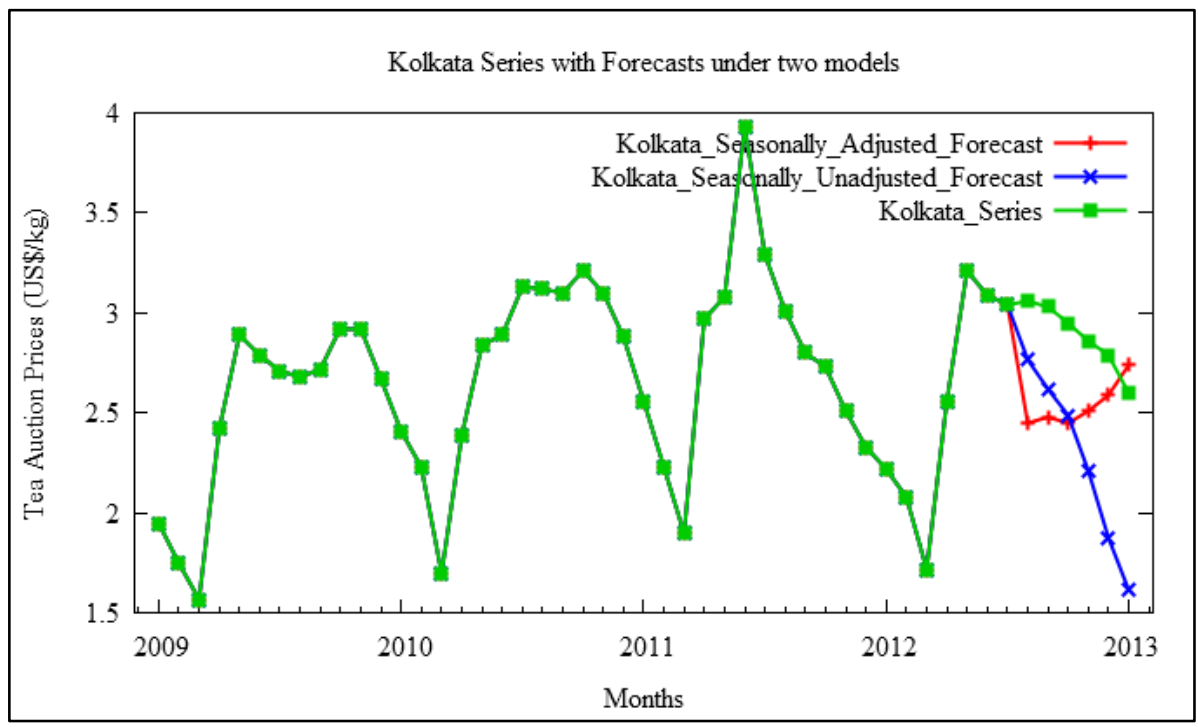

Figure 3: Time series plot of Kolkata series with forecasts obtained from the two models

As seen in the Figure 3, forecasted values for both models deviate from the actual series. However, those values from the SECM follow the pattern of actual data points. Forecasts obtained from VEC depicts completely different pattern compared to actual values. 
Figure 4 represents the forecasting results from the models fitted to seasonally unadjusted and adjusted Guwahati Series.

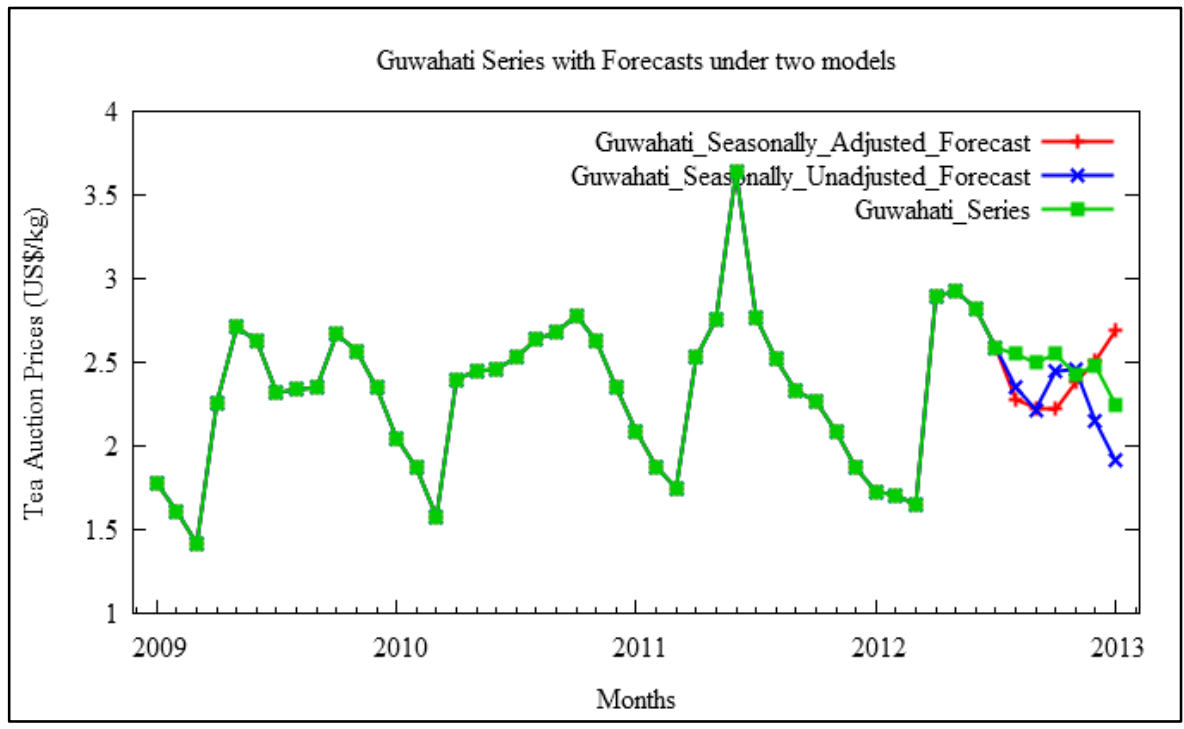

Figure 4: Time series plot of Guwahati series with forecasts obtained from the two models

According to Figure 4, actual data points and the forecasts obtained from the SECM model follow a similar decreasing trend with slight fluctuations. Those values from VEC model follow an increasing trend which is completely different from actual data points. Observing above three figures, it can be suggested that the models fitted capturing the common seasonal patterns is better in the sense of directional prediction as well as value prediction, compared to their counterparts.

Table 9 compares the error measures of the two fitted models, SECM and VECM models. The model (VECM) fitted to seasonally adjusted data shows consistently higher MSE and MAPE values compared to the SECM model over all three locations studied.

According to the ITC (International Tea Committee) bulletin, Colombo, Kolkata, Guwahati and Mombasa are the major tea auction centers in the world. Colombo Auctions holds the record for the highest average auction price for the last three years. Kolkata holds the second largest average auction price and Guwahati is another auction center with higher average auction price. Price valuation of tea at auction centers are done by tasting and considering the market trend and quality of tea and based on factors such as the previous week's price for similar tea. Key factors affecting price movements are tea supply, buying activity in export markets, movements in prices of other auction centers. 
Table 9: Mean Square Error Values of the Models

\begin{tabular}{|l|l|l|l|}
\hline & Colombo & Kolkata & Guwahati \\
\hline $\begin{array}{l}\text { MSE values of Seasonal Model } \\
\text { (SECM) }\end{array}$ & 0.0281 & 0.0476 & 0.0587 \\
\hline $\begin{array}{l}\text { MSE values of model fitted to } \\
\text { seasonally adjusted data (VECM) }\end{array}$ & 0.0655 & 0.1845 & 0.0753 \\
\hline $\begin{array}{l}\text { MAPE values of Seasonal Model } \\
\text { (SECM) }\end{array}$ & 0.0447 & 0.1198 & 0.0875 \\
\hline $\begin{array}{l}\text { MAPE values of model fitted to } \\
\text { seasonally adjusted data (VECM) }\end{array}$ & 0.0656 & 0.1330 & 0.0953 \\
\hline
\end{tabular}

The average prices at the four most important auction centers Kolkata, Guwahati (India); Colombo, (Sri Lanka); and Mombasa, (Kenya) are a reference for the world market price. This may be a reason for the long run relationship to exist between three auction centers Colombo, Kolkata and Guwahati.

\section{Conclusion}

Common seasonal patterns of the tea auction prices have not been used by previous researchers in their studies even though data illustrates seasonality. This empirical study has successfully used common seasonal patterns among the tea auction prices for forecasting. It gives clear evidence that seasonally unadjusted data perform well than seasonally adjusted data for the study period. Forecasting results are more accurate (both in the sense of direction and value) when seasonality is taken in to account.

It may be assumed that seasonality is not a nuisance component and when taken in to consideration, better models can be fitted and more accurate forecasts can be obtained. Filtering out the seasonal components and use of seasonally adjusted data for the analysis may not only lead to loss of important information, but also the true nature of the relationships between these series may not be revealed.

The study identified the seasonal cointegration relationship between Colombo, Kolkata and Guwahati auction prices at two month cycles. Seasonal cointegration relationship between Colombo, Kolkata and Guwahati auction prices at two month frequency suggests that the relationships between these tea auction prices were seasonal in nature and they followed an equilibrium relationship in every 
two month cycles, during the study period. The absence of cointegration at zero frequency unit root for seasonally unadjusted data implies that there was no long run equilibrium between these tea auction prices. The presence of seasonal cointegration relationship led to the use of the seasonal error correction (SECM) model.

Unit root tests confirmed the presence of unit roots at the zero frequency for both unadjusted and adjusted data. The results suggest that tea auction prices were non-stationary and included a common trend. Presence of seasonal unit roots when data were unadjusted suggests that tea auction prices were varying according to seasonal patterns during the period considered.

Lack of prior research studies on SECM and adequacy tests had been a huge difficulty faced when carrying out the analysis. This research area is still in the development phase. None of the statistical packages still provide the procedures to test for seasonal cointegration and to fit Seasonal Error Correction Models (SECM). Developing a procedure to test for seasonal cointegration and to fit SECM is beyond limits of this study. Therefore these tests were conducted manually using the Gretl software.

Commenting on the usefulness of modeling seasonally unadjusted data using only a single set of series may be a weakness of this study. This can be overcome by fitting suitable models for other sets of series. However, it is beyond our objectives.

As further research applications, using the seasonally unadjusted eight series it may be possible to build a Non-linear Autoregressive network with Exogenous inputs (NARX) model to forecast the tea auction prices. This research, considered only the tea auction prices of eight major auction centers. It would be better to consider the variables, tea production and weather of the major tea marketing countries to capture the impact from external factors on the tea auction prices.

\section{Acknowledgements}

Authors are grateful to the Sri Lanka Tea Board for providing the data set for the research.

\section{References}

1. Beaulieu, J. J. and Miron, J. A. (1992). Seasonal Unit Roots in Aggregate U.S. Data. NBER Technical paper series, No. 126. 
2. Dharmasena, K. A. S. D. B. and Bessler, D. A. (2004). Weak Form Efficiency Vs Semi Strong Form Efficiency in Price Discovery: An Application to International Black Tea Markets, Sri Lankan Journal of Agricultural Economics, 6(1), 2004.

3. Engle, R. F., Granger, C. W. J., Hylleberg, S. and Lee, H. S. (1993). Seasonal cointegration: The Japanese consumption function. Journal of Econometrics 55: 275-298. DOI: 10.1016/0304-4076(93)90016-X

4. Gijo, E. V. (2011). Demand forecasting of tea by seasonal ARIMA model. Int. J. Business Excellence, Vol. 4, No. 1, 2011. DOI: 10.1504/ijbex.2011.037252

5. Hylleberg, S., Engle, R. F., Granger, C. W. J. and Yoo, B. S. (1990).Seasonal Integration and Cointegration. Journal of econometrics, 44: 215-238. DOI: 10.1016/0304-4076(90)90080-D

6. Hewapathirana, I. U. and Tilakaratne C. D. (2012). Modeling and Forecasting Sri Lankan black tea prices exploring temporal patterns, Proceedings of the ISM International Statistical Conference 2012, Johor Bharu, Malaysia.

7. Hettiarachchi, H. A. C. K. and Banneheka B.M.S.G. (2012). Time Series Regression and Artificial Neural Network Approaches for Forecasting Unit Price of Tea at Colombo Auction. Journal of the National Science Foundation Sri Lanka, 41: 35-40.

8. Hood, C. C., Ashley, J. D. and Findley, D. F. (2000). An Empirical Evaluation of the Performance of TRAMO/SEATS on Simulated Series. ASA Proceedings, October 2000.

9. Nyaga, E. K. and Doppler. W. (2009).Use of Dynamic Models to Assess Impact of Changing Tea Prices on Family Income of Smallholders in Kenya. Journal of Applied Sciences. 9 (9): 1647 - 1657, 2009. ISSN $1812-5654$.

10. William, R. B. and Hillmer, S.C. (1984). Issues Involved with the Seasonal Adjustment of Economic Time Series. Statistical Research Division Report Series, 84/09. 